ISSN : 2303-1514 | E-ISSN : 2598-5949

DOI : http://dx.doi.org/10.33578/jpfkip.v10i1.8121

https://primary.ejournal.unri.ac.id/index.php/JPFKIP

\title{
UTILIZING TIRE AND CARDBOARD JUMP METHOD TO IMPROVE LONG JUMP STYLE OF SQUATTING ABILITY OF IV GRADE STUDENTS AT SD NEGERI 43 PALEMBANG
}

\author{
I Bagus Endrawan ${ }^{1}$, Sasmarianto ${ }^{2}$ \\ ${ }^{1}$ Universitas Bina Darma, Palembang, Indonesia \\ ${ }^{2}$ Universitas Islam Riau, Pekanbaru, Indonesia \\ 'bagus.endrawan@binadarma.ac.id, ${ }^{2}$ sasmarianto@edu.uir.ac.id
}

\section{PEMBELAJARAN MENGGUNAKAN METODE LOMPAT BAN DAN KARDUS DALAM MENINGKATKAN KEMAMPUAN LOMPAT JAUH GAYA JONGKOK SISWA KELAS IV DI SEKOLAH DASAR NEGERI 43 PALEMBANG}

\begin{tabular}{|c|c|}
\hline ARTICLE HISTORY & ABSTRACT \\
\hline $\begin{array}{l}\text { Submitted: } \\
\text { 06 Oktober } 2020 \\
\text { O6 } 6^{\text {th }} \text { October } 2020\end{array}$ & $\begin{array}{l}\text { Abstract: The type of this study was a class action research aiming at determining the } \\
\text { improvement of students' long jump style of squatting ability by using tire and cardboard jump } \\
\text { at fourth grade of SD Negeri } 43 \text { Palembang. The subjects of the study were } 32 \text { students } \\
\text { consisting of } 15 \text { male students and } 17 \text { female students at the fourth grade. Data were collected } \\
\text { through observation and test. The learning process was conducted in several cycles in order } \\
\text { that students could reach the Minimum Provision Criteria (KKM) established by the school. } \\
\text { The results of the test revealed that } 16 \text { students were complete (50\% of the students reached } \\
\text { KKM) in the pre-cycle. Meanwhile, the results of the test in cycle I found that } 20 \text { students } \\
\text { reached the KKM (62.5\%). Then, in cycle II, the number of students who passed the test } \\
\text { increased to } 26 \text { students }(81.25 \%) \text {, and in cycle III, all students reached KKM (100\%). Thus, it, } \\
\text { could be concluded that the method of tire and cardboard jump improved the students } \\
\text { learning outcomes in long jump style of squatting at SD Negeri } 43 \text { Palembang. }\end{array}$ \\
\hline
\end{tabular}

Keywords: Long Jump Style of Squatting, Tire Jump Method and Cardboard

Accepted:

02 Januari 2021

$02^{\text {nd }}$ January 2021

Published:

20 Februari 2021

$20^{\text {nd }}$ February 2021
Abstrak: Jenis penelitian ini adalah penelitian tindakan kelas yang bertujuan untuk mengetahui peningkatan hasil lompat jauh gaya jongkok siswa dengan menggunakan metode lompat ban dan kardus pada siswa kelas IV Sekolah Dasar Negeri 43 Palembang. Subyek penelitian adalah siswa kelas IV dengan jumlah 32 siswa yang terdiri dari 15 siswa laki laki dan 17 siswa perempuan. Metode pengumpulan data yang dipergunakan adalah Observasi dan tes. Pembelajaran dilakukan melalui beberapa siklus sehingga sampai siswa dapat memenuhi Kriteria Ketentuan Minimal(KKM) yang ditetapkan oleh sekolah. hasil tes pra siklus tuntas 16 orang siswa (50\%), hasil tes siklus I yang tuntas meningkat menjadi 20 orang siswa (62.5\%), dan hasil tes siklus II yang tuntas meningkat lagi menjadi 26 orang siswa (81.25\%), dan pada hasil tes siklus III juga meningkat lagi menjadi 32 orang siswa (100\%). Hasilnya 32 siswa sudah dapat memenuhi standar KKM yang ditetapkan sekolah yaitu sebesar 70. Dengan demikian dapat diambil kesimpulan bahwa dengan metode lompat ban dan kardus dapat memotivasi siswa dalam meningkatkan hasil belajar lompat jah gaya jongkok pada siswa Sekolah Dasar Negeri 43 Palembang.

Kata Kunci: Lompat Jauh Gaya Jongkok, Metode Lompat Ban dan Kardus

\section{CITATION}

Endrawan, I. B., \& Sasmarianto. (2021). Utilizing Tire And Cardboard Jump Method To Improve Long Jump Style Of Squatting Ability Of Iv Grade Students At SD Negeri 43 Palembang . Primary: Jurnal Pendidikan Guru Sekolah Dasar, 10 (1), 102 - 110. DOI: http://dx.doi.org/10.33578/jpfkip.v10i1.8121 . 


\section{PENDAHULUAN}

Pembelajaran merupakan suatu sistem yang terdiri dari berbagai komponen yang saling berhubungan satu dengan yang lainya. Komponen tersebut meliputi: tujuan, materi, metode, danevaluasi. Keempat komponen pembelajaran tersebut harus diperhatikan oleh seorang guru dalam memilih dan menentukan model atau metode pembelajaran agar kegiatan pembelajaran berjalan dengan kondusif. Dalam pembelajaran seorang guru harus mampu menerapkan berbagai model pembelajaran dalam melaksanakan pembelajaranya baik didalam kelas maupun dilapangan, dengan menciptakan pembelajaran yang menarik bagi siswa, akan berdampak positif bagi pertumbuhan dan perkembangan.

Dengan demikian guru sebagai tenaga profesional harus mampu menciptakan atau memodifikasi dengan segala kemampuan aspirasi. (Rusli, 2008: 19). Di dalam pelaksanaan pembelajaran atletik, seorang guru penjaskes dapat memanfaatkan alat-alat yang sederhana. Kreatifitas guru sangat diperlukan untuk melahirkan ide gerak yang mudah dilakukan oleh siswa. Yang teramat penting dari semuanya itu adalah faktor kegembiraan pada anak yang ditimbulkan dari kegiatan atletik, sehingga anak akan tertarik dan mulai menyukai atletik. Untuk mewujudkan suasana yang menggembirakan diperlukan pengembangan atletik yang bernuansa alat, akan lebih menarik jika dilakukan dengan menggunakan alat bantu atau alat peraga hal ini disebabkan karena anak usia Sekolah Dasar memiliki karakteristik tersendiri diantaranya adalah: Anak usia Sekolah Dasar mereka suka bermain, berkelompok, bergerak, cengeng atau manja apalagi untuk kelas rendah, anak usia Sekolah Dasar masih sulit memahami perintah dari gurunya.

Syahab (2010) "Efektivitas Model Pembelajaran Lompat Jauh Gaya Jongkok Dengan Media Kardus Pada Kelas VII SMP N 2 Dari dan Berdasarkan hasil penelitian diperoleh simpulan bahwa pembelajaran lompat jauh dengan menggunakan media kardus memberikan peningkatan.

\section{METODE PENELITIAN}

Penelitian ini berjenis penelitian tindakan kelas (PTK). Penelitian tindakan kelas adalah salah satu strategi pemecahan masalah yang memanfaatkan tindakan nyata dalam bentuk proses pengembangan inovatif yang "dicoba sambil jalan" dalam mendeteksi dan memecahkan masalah (Arikunto, 2006:90). Menurut Wardhani (2007: 14) Penelitian Tindakan Kelas adalah penelitian yang dilakukan oleh guru di dalam kelasnya sendiri melalui refleksi diri, dengan tujuan untuk memperbaiki kinerjanya sebagai guru, sehingga hasil belajar siswa menjadi meningkat. Lokasipenelitianadalahtempatyang digunakandalammelakukan penelitian untuk memperoleh data yang diinginkan. Penelitian ini berlokasi di SDN 43 Palembang padaTahun 2017. Waktu penelitian adalah waktu berlangsungnya penelitian atau saat penelitian ini dilangsungkan. Penelitian inidirencanakan akan dilakukan padabulan april sampai mei semester genap tahun pelajaran 2016/ 2017.

Subjek penelitian ini yaitu siswa kelas IV SDN 43 Palembang. Siswa kelas IV berjumlah 32 orangyang terdiriatas 15 lakilaki dan 17 perempuan. Objek penelitian ini adalah pembelajaran menggunakan metode lompat ban dan kardus dalam meningkatkan kemampuan lompat jauh gaya jongkok siswa kelas IV Sekolah Dasar Negeri 4 Palembang. 


\begin{tabular}{ccccc}
\multicolumn{5}{c}{ Tabel 1. Subjek Penelitian } \\
\hline No & Kelas & Laki Laki & Perempuan & Jumlah \\
1. & IV & 15 & 17 & 32 \\
\hline
\end{tabular}

(Sumber : Tata usaha SDN 43 Palembang, 2017)

\section{HASIL DAN PEMBAHASAN}

Penelitian ini dilakukan dalam upaya meningkatkan kondisi awal kemampuan lompat jauh gaya jongkok siswa kelas IV Sekolah Dasar Negeri 43 Palembang Sumatera Selatan berdasarkan hasil tes awal dari 32 siswa terdapat 16 siswa yang mencapai nilai KKM, yaitu $50 \%$ dari KKM yang telah ditetapkan 70 melalui tahapan-tahapan dalam bentuk siklus berikut ini.

\section{Siklus I}

Di siklus I ini peneliti telah merencanakan kegiatan penelitian sebagai berikut:

a. Perencanaan

Ditahap perencanaan siklus I, peneliti menyiapkan sarana dan prasarana yang akan digunakan dalam penelitian. Adapun peralatan yang perlu disiapkan

adalah sebagai berikut:

1) Menyiapkan Rencana Pelaksanaan pembahasan materi lompat jauh.

2) Menyiapkan lembar pengamatan untuk mengumpulkan data kemampuan siswa dalam kemampuan lompat jauh.

3) Menyiapkan peralatan yang akan digunakan dalam pembelajaran

b. Tindakan

Tindakan yang dilakukan di siklus pertama adalah:

1) Siswa melakukan pembelajaran lompat ban dan kardus secara bergantian setelah melakukan lompatan sebanyak 2-3 kali pengulangan dilakukan selama dua putaran, dan diganti siswa yang lain, sampai semua siswa mendapat giliran;

2) Peneliti memberikan intruksi dan aturan kepada siswa. Peneliti berperan sebagai penilaian yang memberikan arah atau aturan yang baik berdiri di samping siswa dengan jarak 2-3 meter. Setelah masing-masing siswa mendapat giliran melompat, siswa diganti sampai semua anak mendapat giliran.

c. Pengamatan atau observasi

Selama proses tindakan dilakukan, peneliti melakukan pengamatan dengan menggunakan lembar observasi. Dari data yang terkumpul kemudian digunakan sebagai evaluasi di akhir setiap kegiatan pembelajaran berlangsung. Peningkatan kemampuan lompat jauh gaya jongkok siswa Kelas IV Sekolah Dasar Negeri 3 Ngunang Kabupaten Musi Banyuasin dari semula yang tuntas 10 orang siswa $(54.54 \%)$ meningkat menjadi 14 orang siswa $(63.63 \%)$ yang mencapai ketuntasan atau terjadi peningkatan sebesar $9.09 \%$.

d. Refleksi

Refleksi dilakukan dengan membandingkan dari hasil kemampuan siswa dalam melakukan lompat jauh gaya jongkok hasil tes awal/ pra siklus dengan hasil setelah proses tindakan siklus I. Hasil tes siklus I tersebut menunjukkan terjadinya peningkatan kemampuan lompat jauh gaya jongkok siswa Kelas IV Sekolah Dasar Negeri 4 Palembang dari yang semula yang tuntas 16 orang siswa (50\%) meningkat menjadi 20 orang siswa $(62.5 \%)$ yang mencapai ketuntasan atau terjadi peningkatan sebesar $12.5 \%$. Jika hasilnya belum sesuai dengan KKM yang telah ditetapkan, maka tindakan di siklus I dinilai belum berhasil dan dilanjutkan ke siklus berikutnya yaitu siklus II. 


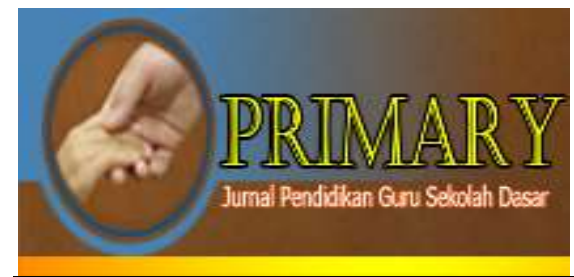

\section{PRIMARY: JURNAL PENDIDIKAN GURU SEKOLAH DASAR \\ VOLUME 10 NOMOR 1 FEBRUARI 2021 \\ ISSN : 2303-1514 | E-ISSN : 2598-5949 \\ DOI : http://dx.doi.org/10.33578/jpfkip.v10i1.8121 \\ https://primary.ejournal.unri.ac.id/index.php/JPFKIP}

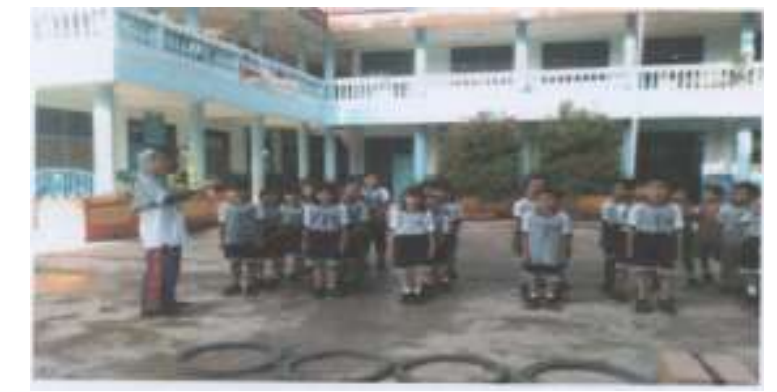

Gambar 1. Peneliti Memberikan Aturan Lompat

Dari tabel nilai hasil tes siklus I tersebut dapat dikategorikan seperti pada tabel berikut ini:

Tabel 2. Distribusi Frekuensi Siklus I

\begin{tabular}{lccc}
\hline \multicolumn{1}{c}{ Kategori } & $\begin{array}{c}\text { Rentang } \\
\text { Nilai }\end{array}$ & Frekuensi & Persentase \\
\hline Sangat baik & $85-100$ & 2 & $6.25 \%$ \\
Baik & $75-84$ & 6 & $18.75 \%$ \\
Cukup & $65-74$ & 12 & $37.5 \%$ \\
Kurang & $45-64$ & 4 & $12.5 \%$ \\
Sangat & & & $25 \%$ \\
kurang & $\leq 44$ & 8 & $100 \%$ \\
\multicolumn{2}{l}{ Jumlah } & 32 & \\
\hline
\end{tabular}

Dari tabel distribusi frekuensi siklus I tersebut, agar lebih jelasnya dapat disajikan dalam bentuk histogram berikut ini:

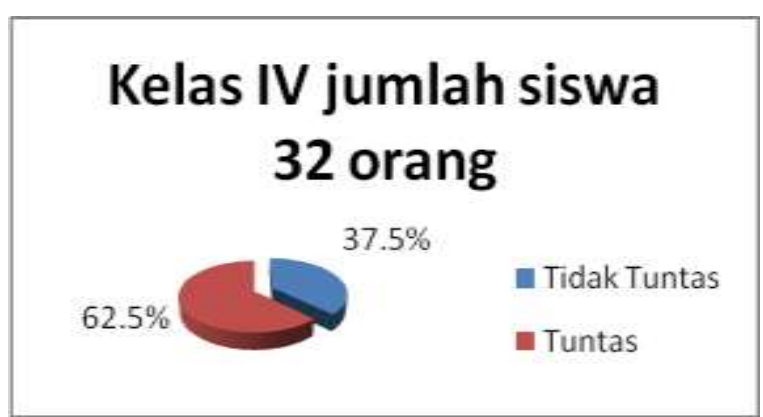

Gambar 2. Histogram Siklus

Siklus II

Kegiatan siklus II merupakan lanjutan dari kegiatan siklus I yang perlu perbaikan dan penyempurnaan sesuai dengan kesulitan dan kendala yang timbul. Di siklus II siswa melakukan lompat ban dan kardus diberikan perhatian yang lebih khusus agar siswa tidak bermain main saat melakukan lompat ban dan kardus serta peneliti menambah jumlah pengulangan lompatan dari yg diberi 
kesempatan 2 kali pada siklus sebelumnya pada siklus ke II siswa diberikan kesempatan 3-5 kali kesempatan melompati ban dan kardus. Kegiatan siklus II adalah sebagai berikut:

Perencanaan

Perencanaan di siklus II, peneliti menyiapkan sarana dan prasarana yang akan digunakan dalam penelitian. Adapun peralatan yang perlu disiapkan adalah sebagai berikut:

1) Menyiapkan Rencana Pelaksanaan Pembelajaran (RPP) dengan materi pembahasan atletik khususnya lompat jauh gaya jongkok.

2) Menyiapkan lembar pengamatan untuk mengumpulkan data kemampuan siswa dalam kemampuan lompat jauh gaya jongkok..

3) Menyiapkan peralatan yang akan digunakan dalam perlakuan/ kegiatan pembelajaran.

a. Tindakan
Tindakan yang dilakukan di siklus kedua adalah Siswa melakukan pembelajaran lompat ban dan kardus secara bergantian setelah melakukan lompatan sebanyak 2-3 kali pengulangan dilakukan selama dua putaran, dan diganti siswa yang lain, sampai semua siswa mendapat giliran;

b. Pengamatan atau observasi

Selama proses tindakan, peneliti melakukan pengamatan dengan menggunakan lembar observasi. Dari data yang terkumpul kemudian digunakan sebagai evaluasi di akhir setiap kegiatan pembelajaran. Peningkatan kemampuan lompat jauh gaya jongkok siswa Kelas IV Sekolah Dasar Negeri 4 Palembang dari semula yang tuntas 20 orang siswa $(62.5 \%)$ meningkat menjadi 26 orang siswa $(81.25 \%)$ yang mencapai ketuntasan atau terjadi peningkatan sebesar $19 \%$.

Dari tabel nilai hasil tes siklus II dapat dikategorikan seperti berikut ini:

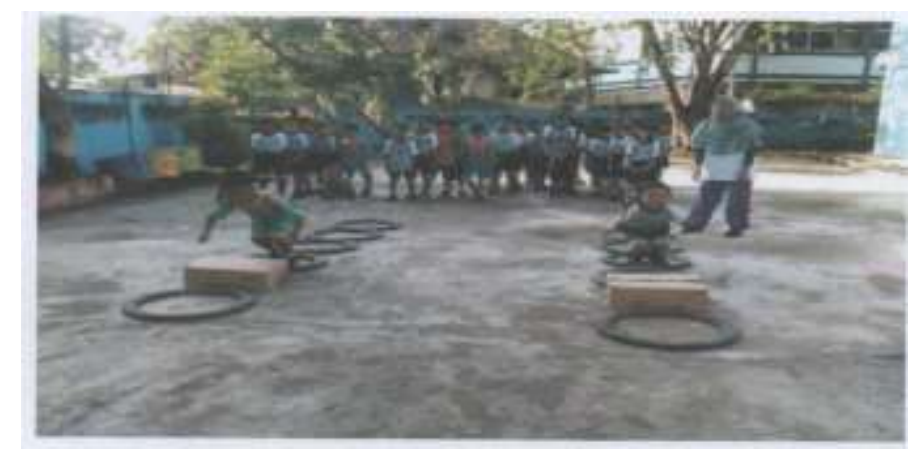

Gambar 3. Siswa Melakukan Lompat Ban dan Kardus

Tabel 3. Distribusi Frekuensi Siklus II

\begin{tabular}{lccc}
\hline \multicolumn{1}{c}{ Kategori } & $\begin{array}{c}\text { Rentang } \\
\text { Nilai }\end{array}$ & Frekuensi & Persentase \\
\hline Sangat baik & $85-100$ & 2 & $6.25 \%$ \\
Baik & $75-84$ & 6 & $18.75 \%$ \\
Cukup & $65-74$ & 18 & $56.25 \%$ \\
Kurang & $45-64$ & 0 & $0 \%$ \\
$\begin{array}{l}\text { Sangat } \\
\text { kurang }\end{array}$ & $\leq 44$ & 6 & $18.75 \%$ \\
\multicolumn{2}{c}{ Jumlah } & 32 & $100 \%$ \\
\hline
\end{tabular}


Dari tabel di atas, untuk lebih jelasnya

berikut ini: dapat juga disajikan dalam bentuk histogram

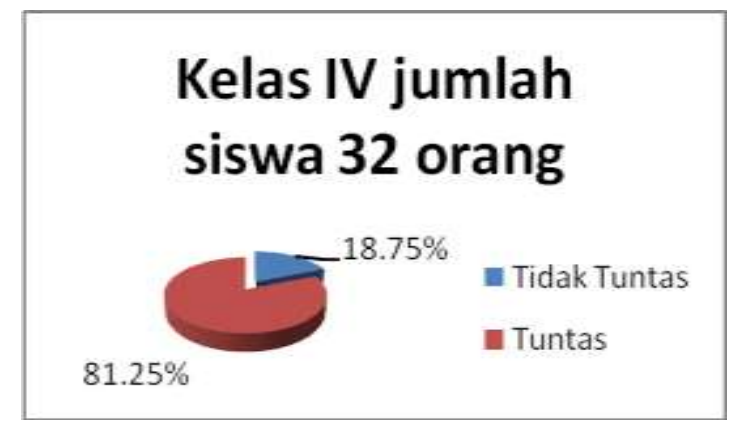

Gambar 4. Histogram Siklus II

\section{c. Refleksi}

Refleksi dilakukan dengan membandingkan dari hasil kemampuan siswa dalam melakukan lompat jauh gaya jongkok hasil siklus I dan siklus II dengan hasil setelah proses tindakan siklus II. Hasil tes siklus II tersebut menunjukkan terjadinya peningkatan kemampuan lompat jauh gaya jongkok siswa Kelas IV Sekolah Dasar Negeri 43 Palembang dari yang semula yang tuntas 20 orang siswa $(62.5 \%)$ meningkat menjadi 26 orang siswa $(81.25 \%)$ yang mencapai ketuntasan atau terjadi peningkatan sebesar $18.75 \%$. Jika hasilnya belum sesuai dengan KKM yang telah ditetapkan, maka tindakan di siklus II dinilai belum berhasil dan dilanjutkan ke siklus berikutnya yaitu siklus III.

Refleksi II dilakukan dengan membandingkan dari hasil kemampuan siswa dalam melakukan lompat jauh gaya jongkok hasil siklus I dan siklus II dengan hasil setelah proses tindakan siklus III. Hasil tes siklus III tersebut menunjukkan terjadinya peningkatan kemampuan lompat jauh gaya jongkok siswa Kelas IV Sekolah Dasar Negeri 43 Palembang dari yang semula yang tuntas 26 orang siswa $(81.25 \%)$ meningkat menjadi 32 orang siswa (100\%) yang mencapai ketuntasan atau terjadi peningkatan sebesar $18.75 \%$. Karena telah mencapai $100 \%$, maka penelitian ini dinyatakan berhasil.

\section{Pembahasan}

Hasil pelaksanaan setiap siklus yang dilakukan oleh peneliti terjadi peningkatan secara berturut-turut hasilnya sebagai berikut: 1) hasil tes pra siklus tuntas 16 orang siswa atau presntase ketuntasan (50\%). Maka diadakan upaya untuk melakukan peningkatan dengan menggunakan metode yang dianggap tepat untuk meningkatkan kemampuan lompat jauh gaya jongkok siswa Kelas IV Sekolah Dasar Negeri 43 Palembang. 2) Setelah menjalani berbagai macam tindakan hasil tes siklus I yang tuntas meningkat menjadi 20 orang siswa (62.5\%) atau terjadi peningkatan sebesar $(12.5 \%)$. Jika hasilnya belum sesuai dengan KKM yang telah ditetapkan, maka tindakan di siklus I dinilai belum berhasil dan dilanjutkan ke siklus berikutnya dan tentunya tindakan yang diberikan berbeda dengan siklus pertama atau lebih ditingkatkan 3) setelah mengalami berbagai macam tindakan hasil tes siklus II yang tuntas meningkat menjadi 26 orang siswa $(81.25 \%)$ atau terjadi peningkatan sebesar (18.75\%). Karena penilaian KKM belum sesuai yang diharapkan maka penelitian ini dilanjutkan ke siklus berikutnya. 4) dan setelah mengalami berbagai macam tindakan hasil tes siklus III meningkat menjadi 32 orang siswa atau presntase sebesar (100\%) atau terjadi peningkatan sebesar $18.75 \%$ dan penelitian dinyatakan berhasil atau tuntas. 
Hasil ketuntasan tes setiap siklus dapat dilihat

seperti tabel berikut ini:

Tabel 4. Nilai Ketuntasan Setiap Siklus

\begin{tabular}{ccccl}
$\begin{array}{c}\text { Jumlah } \\
\text { siswa }\end{array}$ & Siklus & Tuntas & Keterangan \\
\hline 32 & $\begin{array}{c}\text { Pra } \\
\text { siklus }\end{array}$ & 16 & $50 \%$ & Kon. Awal \\
32 & I & 20 & $62.5 \%$ & B. berhasil \\
32 & II & 26 & $81.25 \%$ & B. berhasil \\
32 & III & 32 & $100 \%$ & Berhasil \\
\hline
\end{tabular}

Dari tabel nilai ketuntasan setiap siklus di atas, untuk lebih jelasnya dapat juga disajikan dalam bentuk diagram berikut ini:

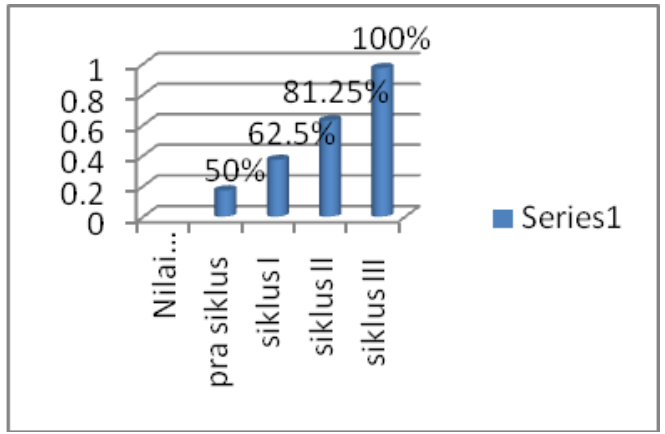

\section{Gambar 5. Diagram Ketuntasan Setiap Siklus}

\section{Hasil Peningkatan}

Pra siklus/ kondisi awal tuntas 16 orang siswa (50\%). Dari pra siklus ke siklus I terjadi peningkatan ketuntasan 4 orang siswa (12.5\%). Dari siklus I ke siklus II terjadi peningkatan 6 orang siswa (18.75\%). dan dari siklus II ke siklus III terjadi peningkatan ketuntasan 6 orang siswa (18.75\%). Hasil peningkatan setiap siklus dapat dilihat pada tabel berikut ini:

\section{Tabel 5. Hasil Peningkatan Setiap Siklus}

\begin{tabular}{|c|c|c|c|c|}
\hline \multicolumn{5}{|c|}{ Hasil Peningkatan } \\
\hline $\begin{array}{l}\text { Pra } \\
\text { siklus }\end{array}$ & Kondis & nta & 6 orang siswa & $50 \%$ \\
\hline $\begin{array}{l}\text { Siklus I } \\
\text { Siklus }\end{array}$ & 16 & 20 & 4 & $12.5 \%$ \\
\hline $\begin{array}{l}\text { II } \\
\text { Siklus }\end{array}$ & 20 & 26 & 6 & $18.75 \%$ \\
\hline III & 26 & 32 & 6 & $18.75 \%$ \\
\hline
\end{tabular}


iㅔ

Jumal Pendidkan Eun Sekolah Daser
PRIMARY: JURNAL PENDIDIKAN GURU SEKOLAH DASAR

VOLUME 10 NOMOR 1 FEBRUARI 2021

ISSN : 2303-1514 | E-ISSN : 2598-5949

DOI : http://dx.doi.org/10.33578/jpfkip.v10i1.8121

https://primary.ejournal.unri.ac.id/index.php/JPFKIP

Dari tabel hasil peningkatan setiap siklus tersebut, agar lebih jelas dapat disajikan dalam

bentuk

diagram

berikut

ini

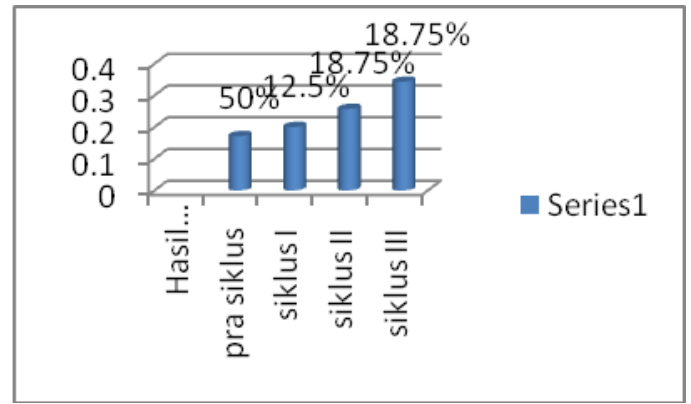

\section{Gambar 6. Diagram Peningkatan Setiap Siklus}

\section{SIMPULAN DAN REKOMENDASI}

Dari hasil Penelitian Tindakan Kelas yang telah dilakukan dalam tiga siklus, maka dapat disimpulan seperti berikut ini:

1. Lompat jauh dengan menggunakan metode melompati ban dan kardus sangat efektif dalam meningkatkan kemampuan lompat jauh gaya jongkok siswa kelas IV Sekolah Dasar Negeri 43 Palembang dari kondisi awal/nilai pra siklus tuntas 16 orang siswa $(50 \%)$ di siklus I meningkat menjadi 20 orang siswa (62.5\%) atau terjadi peningkatan ketuntasan sebesar $12.5 \%$.

2. Siklus II Lompat jauh dengan menggunakan metode melompati ban dan kardus sangat efektif dalam meningkatkan kemampuan lompat jauh gaya jongkok siswa kelas IV Sekolah Dasar Negeri 43 Palembang dari kondisi siklus I tuntas 20 orang siswa $(62.5 \%)$ di siklus II meningkat menjadi 26 orang siswa $(81.25 \%)$ atau terjadi peningkatan sebesar $18.75 \%$

3. Dan disiklus III Lompat jauh dengan metode lompat ban dan kardus sangat efektif dalam meningkatkan kemampuan lompat jauh gaya jongkok siswa kelas IV Sekolah Dasar Negeri 43 Palembang dari kondisi siklus II tuntas 26 orang siswa $(81.25 \%)$ siklus III meningkat menjadi 32 orang siswa $(100 \%)$ atau terjadi peningkatan sebesar $18.75 \%$. Berdasarkan dari pernyataan di atas dapat disimpulkan bahwa adanya peningkatan kemampuan lompat jauh gaya jongkok siswa kelas IV Sekolah Dasar Negeri 43 Palembang.

\section{DAFTAR PUSTAKA}

Adisuyanto., \& Biasworo. (2009). Cerdasdan Bugar dengan Senam Lantai. Surabaya: Gramedia.

Diaksesmelaluihttp://books.google.co.id Ahmad, Y. (2007). Belajar Gerakdan Teknik Senam Lantai. Semarang: CV. Aneka Ilmu.

Arikunto. (2010). Prosedur Penelitian Suatu Pendekatan Praktek. Jakarta: Rineka Cipta.

Dantes. (2012). Metode Penelitian. Andi: Yogyakarta.

Hamalik. (2008). Unsur-unsur Pembelajaran disekolah. Surabaya: Rineka Cipta.

Karwono. (2008). Metode Penelitian Aplikasih Praktis Pembuatan Proposal Dan Laporan Penelitian. Malang: UMMPres. Kunandar. (2008). Penelitian Tindakan Kelas. Bandung: YramaWidya. 
Mailah. (2007). Gymnastic. Universitas Persatuan Guru Republik Indonesia Palembang.

Mahendra. (2001). Ilmu Atletik. Bandung: Yrama Widya..

Moeslim. (2005) .Penuntun Pelajaran Praktek Senam. Bandung: STO.

Mujahir. (2013). Pendidikan Jasmani, Olahraga, dan Kesehatan. Jakarta: Erlangga.

Mukholid, A. (2007). Senam Lantai dan Kebugaran Jasmani. Jakarta: Laskar Aksara.

Roji. (2009). Pendidikan Jasmani Olahraga dan Kesehatan Olahraga tingkat anak sekolah dasar. Jakarta: Erlangga.

Sudjarwo. (2012). Belajar Senam Lantai. http://olahragasehat.blogspot.com,Diak ses20April2015.

Sugiyono. (2010). Metode Penelitian Kuantitatif dan Kualitatif: Dilengkapi Metode $R \& D$. Alfabeta: Bandung.

Tilarso. (2010). Fase Gerakan-gerakan dasar senam lantai. Bandung: Bintang Harapan.

Traetta, M. J. (2008). Dasar Dasar Senam. Bandung: Angkasa.

Wardani, B. (2011). Metode Penelitian Kualitatif. Jakarta: PT Raja Gapindo Persa. 